\section{Hemoglobin Interlaken in combination with beta thalassemia trait}

\author{
Mara J. Ojeda, ${ }^{1}$ Susana M. Perez, ${ }^{1}$ \\ Karina L. Calvo, ${ }^{1}$ Arianna F. Pratti, ${ }^{1}$ \\ María E. Voss, ${ }^{1}$ Angela C. Milani, ${ }^{1}$ \\ Gustavo Chiappe, ${ }^{2}$ Beatriz Erramouspe, ${ }^{2}$ \\ Irma M. Bragós ${ }^{1}$ \\ ${ }^{1}$ Cátedra Hematología, Facultad Ciencias \\ Bioquímicas y Farmacéuticas, \\ Universidad Nacional de Rosario, \\ Rosario, Santa Fe, Argentina; \\ 2Unidad Asistencial Dr. César Milstein, \\ Ciudad Autónoma de Buenos Aires, \\ Argentina
}

\section{Abstract}

We report a rare $\alpha 1$ globin gene variant $(\mathrm{Hb}$ Interlaken) found in a 63-year-old woman of Italian ancestry living in Buenos Aires Province, Argentina. The variant, a missense mutation at cd15 (GGT $\rightarrow$ GAT) causing a Gly $\rightarrow$ Asp amino acid substitution and also known as $\mathrm{Hb} \mathrm{J}$ Oxford, was found in combination with the common thalassemia trait $c d 39(\mathrm{C} \rightarrow \mathrm{T})$. The clinical picture of the patient was that of a $\beta$-thalassemia trait.

\section{Introduction}

In 1964 Liddell first described hemoglobin Interlaken in an English family. ${ }^{1}$ Only isolated reports exist in which the same mutation was named $\mathrm{Hb} \mathrm{J}-\mathrm{Oxford}$ or $\mathrm{Hb} \mathrm{N}-\mathrm{Cosenza}^{2}$ The variant has thus far been described in combination with $\beta$-thalassemia homozygosity and $\mathrm{HbS}$ but not in combination with $\beta$-thalassemia trait and never before in Argentina, a multi ethnic country with many ethnic components.

$\mathrm{Hb}$ Interlaken is a stable $\alpha 1$ chain variant caused by a GAC $\rightarrow$ CAC transversion at codon 15 of the $\alpha 1$ gene causing a Gly $\rightarrow$ Asp amino acid substitution (HGVS nomenclature HBA1:c. $47 \mathrm{G}>\mathrm{A}){ }^{3}{ }^{3}$

\section{Case Report}

We report the identification of $\mathrm{Hb}$ Interlaken in a 63-year-old Argentinian woman of Italian ancestry, referred to our laboratory because of a microcytic hypocromic anemia. $\mathrm{Hb}$ Interlaken was found in this patient in combination with the common Mediterranean $\beta^{0}$ tha- lassemia trait cd $39(\mathrm{C} \rightarrow \mathrm{T})$ (HGVS nomenclature HBB:c.118C $>\mathrm{T}$ ), the most frequent $\beta$ - thalassemia mutation in Argentina. ${ }^{4}$

Complete blood count (CBC) was obtained with a Coulter Counter model ACT10 (Beckman Coulter Inc, Brea, CA, USA): Hb (g/L) 11.6, RBC (1012/L) 5.88, MCV (fL) 62.4, HCM (pg) 19.7, reticulocytes (\%) 1.0.

The separation of the $\mathrm{Hb}$ fractions was done on alkaline cellulose acetate electrophoresis (Figure 1A). The presence of a $\mathrm{J}$ like minor fraction was suggestive for an $\alpha$ chain variant. $\mathrm{Hb}$ A2 measured by elution from electrophoresis followed by spectrophotometric measurement of the absorbance at $415 \mathrm{~nm}$ was estimated at $3 \%$ while $\mathrm{Hb} \mathrm{X}$ was $28 \%$. In spite of the normal $\mathrm{HbA}_{2}$ level, the $\mathrm{CBC}$, the slightly elevated $\mathrm{HbF}(1.3 \%)$ estimated according to Betke $e t$ $a l^{5,6}$ indicated a possible $\beta$-thalassemia trait while the very low mean corpuscolar hemoglobin could be an indication for a $\beta-/ \alpha$ thalassemia combination. Iron parameters were measured as previously described: ${ }^{7}$ serum iron $56 \mathrm{ug} / \mathrm{dL}$, total iron-binding capacity 328 ug/dL, transferrin saturation $17 \%$ and serum ferritin $4 \mathrm{ng} / \mathrm{mL}^{8}{ }^{8}$ Isopropanol, ${ }^{9}$ heat stability and sickle tests were performed and were all negative.

DNA was extracted from peripheral blood sample. ${ }^{10}$ Amplification refractory mutation system-polymerase chain reaction (ARMSPCR) ${ }^{11}$ was used to confirm the presence of the $\beta^{039}$ mutation (data not shown).

Alpha thalassemia deletion analysis was done using Gap-PCR ${ }^{12}$ taking into account the ethnic origin and hematological data of the patient while for point mutation analysis amplification of the $\alpha 2$ - and $\alpha 1$-globin genes was performed as previously described by using oligonucleotide primers (CyberSyn, Lenni, PA, USA); the common forward primers FAa2: 5'-CGCGCTCGCGGCCCGGCAC-3', and reverse specific primers for the $\alpha 2$ gene: 5 'GGGAGGCCCATCGGGCAGGAGGAAC-3' and $\alpha 1$ gene: 5'-GGGGGGAGGCCCAAGGGGCAAGAA-3'. Sequencing was done using a Big Dye Terminators Ready Reaction Kit (Perkin-Elmer Cetus, Norwalk, CT, USA) in an ABI PRISM 310 sequencer (Perkin-Elmer Cetus). Primers used for sequencing the two genes were the following: exon 1, common forward primers FAa2; exon 2, primer S2 (5'-CCCGCCCGGACCCACA-3'); exon 3, primer S3 (5'GCGGGTTGCGGGAGGT-3'). The reverse specific primers for the $\alpha 1$ gene were used to confirm the mutation.

GAP-PCR were used to detect $\alpha^{0}$ deletions $(\alpha) 20.5,-$ MED and $\alpha^{+}$deletions $-\alpha^{3.7}$ and $\alpha^{4.2}$ and were all negative. Sequencing of $\alpha 1$ gene revealed a $\mathrm{GAC} \rightarrow \mathrm{CAC}$ (Asp $\rightarrow$ His) substitution at codon 15 , corresponding to $\mathrm{Hb}$ Interlaken (Figure 1B).

Even though $\mathrm{Hb}$ Interlaken is detectable by electrophoresis a correct characterization of
Correspondence: Irma M. Bragós, Cátedra Hematología, Facultad Ciencias Bioquímicas y Farmacéuticas, Universidad Nacional de Rosario, Rosario, Santa Fe, Argentina.

Tel. +54.341.4804592/3 - Fax: +54.341 .4804598 . E-mail: ibragos@fbioyf.unr.edu.ar

Key words: thalassemia, hemoglobinopathies microcytic hypocromic anemia, Hb Interlaken.

Acknowledgments: we are very grateful to Dr M.C. Rosatelli from the Istituto di Clinica e Biologia dell'Età Evolutiva, Università degli Studi Cagliari, Italy who provided DNA samples with known mutations.

Contributions: IMB, MJO, conception and design; IMB, SMP, MJO, BE, GC, AFP, MEV, development of methodology; IMB, GC, BE, acquisition of data; IMB, SMP, MJO, KLC, GC, BE, AFPratti, MEV, analysis and interpretation of data; IMB, SMP MJO, KLC, ACM, writing, review and/or revision of the manuscript; IMB, KLC, AFP, MEV, ACM, administrative, technical, or material support IMB, SMP, MJO, ACM, study supervision.

Conflict of interests: the authors report no conflict of interests.

Received for publication: 10 October 2012.

Revision received: 14 December 2012.

Accepted for publication: 7 January 2012.

This work is licensed under a Creative Commons Attribution 3.0 License (by-nc 3.0).

(C) Copyright I.M. Bragós et al., 2013

Licensee PAGEPress, Italy

Thalassemia Reports 2013; 3:e3

doi:10.4081/thal.2013.e3

the genotype requires better methods, especially in combination with and $\alpha$ thalassemia. Then more sophisticated systems able to measure $\mathrm{Hb}$ fractions more precisely like highperformance liquid chromatography or capillary electrophoresis ${ }^{13}$ are needed before molecular analysis.

In our case the estimation of the $\mathrm{HbA}_{2}$ that should have been elevated was typically normal risking misdiagnosis. The underestimation was due to the fact that part of the delta chain is bound by the mutated $\alpha$ chain and this abnormal $\mathrm{HbA}_{2}$ fraction migrates on a different spot and is lost for measurement. Therefore the measured $\mathrm{HbA} 2$ value (3\%) should be augmented by $28 \%$ resulting into a $3.84 \%$ a still ambiguous but elevated $\mathrm{HbA}_{2}{ }^{6}$ Even though our value $(28 \%)$ for hemoglobin variant $\mathrm{J}$ Oxford is high, the consulted references showed values between 21 and 25\%. ${ }^{14-16}$

It is the first time that this abnormal hemoglobin is described in our country. The low red blood cell indexes observed in this case are due to co-inheritance of $\beta^{0}$ thalassemia and the underestimation of $\mathrm{HbA}_{2}$ could be caused 

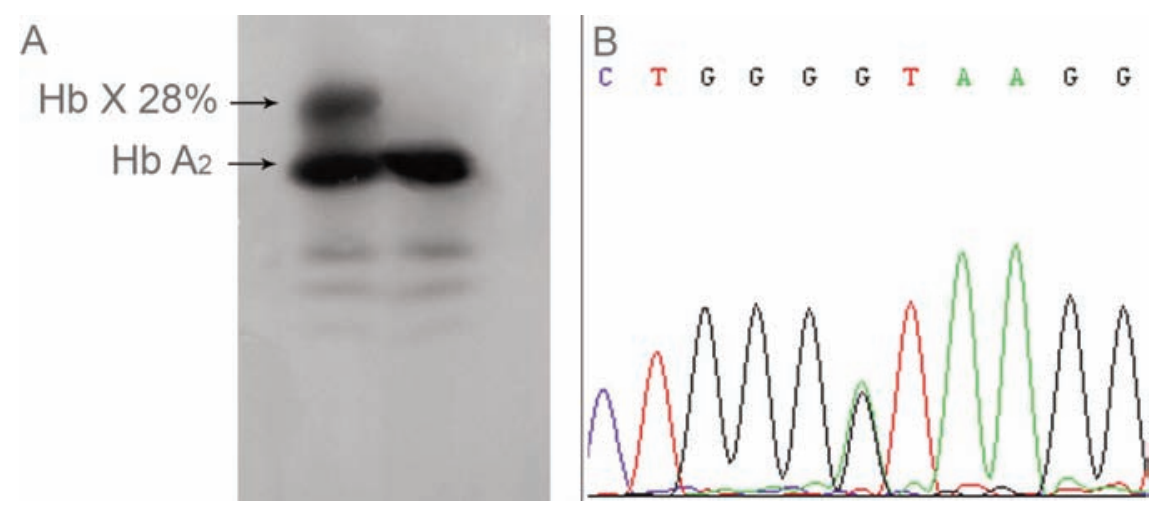

Figure 1. A) Hemoglobin electrophoresis at alkaline $\mathrm{pH}$. B) Sequencing of the $\alpha 1$-globin gene showed one mutation corresponding to $\mathrm{Hb}$ Interlaken $(\mathrm{Hb} \mathrm{J}$-Oxford, $\mathrm{Hb} \mathrm{N}$ Cosenza), [ $\alpha 15$ Gly $\rightarrow$ Asp, GGT $>$ GAT $]$.

by iron deficiency in the patient at the time of diagnosis and lost of the abnormal $\mathrm{HbA}_{2}$ fraction.

\section{References}

1. Liddell J, Brown D, Beale D, et al. A new Haemoglobin-Ja Oxford found during a survey of an English population. Nature 1964;204:269-70.

2. Schiliro G, Musumeci S, Pizzarelli G, et al. A new alkali-resistant hemoglobin $\alpha 2 \mathrm{~J}$ Oxford gammaF2 in a Sicilian baby girl with homozygous $\beta^{0}$ thalassemia. Blood 1976;48:639-51.

3. Molchanova TP, Pobedimskaya DD, Huisman, TH. The differences in quantities of $\alpha 2$ - and $\alpha 1$-globin gene variants in heterozygotes. Br J Haematol 1994;88:3006 .

4. Bragós I, Noguera N, Morisoli L, Milani A. Most frequent mutations in $\beta$-thalassemia in a population in Rosario, Argentina. Haematologica 2000;85:101-2.

5. Betke K, Marti HR, Schlicht I. Estimation of small percentages of foetal haemoglobin. Nature 1959;184 Suppl 24:1877-8.

6. Stephens AD, Angastiniotis M, Baysal E, et al. International Council for the Standardisation of Haematology (ICSH). ICSH recommendations for the measurement of haemoglobin $\mathrm{A}_{2}$. Int J Lab Hematol 2012;34:1-13.

7. International Committee for Standardization in Haematology (ICSH). The measurement of total and saturated Ironbinding capacity in serum. Br J Haematol 1978b;38:281-7.
8. Cazzola M. Metodologia e strategia per lo studio di laboratorio del metabolismo del ferro. Clinica e Laboratorio 1989;13:2.

9. Carrell RW, Kay R. A simple method for the detection of unstable haemoglobins. Br J Haematol 1972;23:615-9.

10. Noguera N, Tallano C, Bragós I, Milani A. Modified salting-out method for DNA isolation from newborn cord blood nucleated cells. J Clin Lab Analysis 2000;14;280-3.

11. Old JM, Varawalla NY, Weatherall DJ. Rapid detection and prenatal diagnosis of $\beta$-thalassaemia: studies in Indian and Cypriot populations in the UK. Lancet 1990 336:834-7.

12. Liu YT, Old JM, Miles K, et al. Rapid detection of -thalassaemia deletions and -globin gene triplication by multiplex polymerase chain reactions. Br J Haematol 2000;108:295-9.

13. Van Delft P, Lenters E, Bakker-Verweij M, et al. Evaluating five dedicated automatic devices for haemoglobinopathy diagnostics in multi-ethnic populations. Int $\mathrm{J}$ Lab Hematol 2009;31:484-95.

14. Caruso D, Crestani M, Da Riva L, et al. Mass spectrometry and DNA sequencing are complementary techniques for characterizing hemoglobin variants: the example of hemoglobin J-Oxford. Haematologica 2004;89:608-9.

15. Schiliró G, Musumeci S, Pizzarelli G, et al. A new alkali-resistant hemoglobin $\alpha 2 \mathrm{~J}$ Oxford gammaF2 in a Sicilian Baby Girl With Homozygous $\beta^{0}$ Thalassemia. Blood 1976;48:639-44.

16. Gilcher R0, Bromberg PA, Finn FM, Jensen WN. Hemoglobin JOxford: effects on hemoglobin and erythrocyte function. Blood 1968;32:260-70. 